\title{
Transcriptomic analysis of resistance and short- term induction response to pyrethroids, in Anopheles coluzzii legs
}

\section{Mary Kefi}

Department of Biology, University of Crete, Vassilika Vouton, 71409, Heraklion Jason Charamis

Department of Biology, University of Crete, Vassilika Vouton, 71409, Heraklion

\section{Vasileia Balabanidou}

Institute of Molecular Biology and Biotechnology, Foundation for Research and Technology-Hellas, 70013 Heraklion

\section{Panagiotis loannidis}

Institute of Molecular Biology and Biotechnology, Foundation for Research and Technology-Hellas, 70013 Heraklion

\section{Hilary Ranson}

Department of Vector Biology, Liverpool School of Tropical Medicine, Pembroke Place, Liverpool

\section{Victoria A Ingham}

Parasitology Unit, Universitätsklinikum Heidelberg, Im Neuenheimer Feld 324, 69120 Heidelberg John Vontas ( $\square$ vontas@imbb.forth.gr)

Pesticide Science Laboratory, Department of Crop Science, Agricultural University of Athens, 11855 Athens

\section{Research Article}

Keywords: Anopheles coluzzii, legs, constitutive insecticide resistance, short-term induction, deltamethrin, transcriptomics

Posted Date: September 22nd, 2021

DOl: https://doi.org/10.21203/rs.3.rs-904452/v1

License: (a) (i) This work is licensed under a Creative Commons Attribution 4.0 International License. Read Full License

Version of Record: A version of this preprint was published at BMC Genomics on December 1st, 2021. See the published version at https://doi.org/10.1186/s12864-021-08205-w. 



\section{Transcriptomic analysis of resistance and short- term induction response to pyrethroids, in Anopheles coluzzii legs}

Kefi M. ${ }^{1,2^{*}}$, Charamis J.1,2* , Balabanidou V. ${ }^{2}$, Ioannidis P. ${ }^{2}$, Ranson H.3, Ingham VA.3,4, Vontas J2,5*

${ }^{1}$ Department of Biology, University of Crete, Vassilika Vouton, 71409, Heraklion, Greece

2Institute of Molecular Biology and Biotechnology, Foundation for Research and Technology-Hellas, 73100 Heraklion, Greece

3Department of Vector Biology, Liverpool School of Tropical Medicine, Pembroke Place, Liverpool, UK

4Parasitology Unit, Universitätsklinikum Heidelberg, Im Neuenheimer Feld 324, 69120 Heidelberg, Germany

5Pesticide Science Laboratory, Department of Crop Science, Agricultural University of Athens, 11855 Athens, Greece

*equal contribution 


\section{Abstract}

\section{Background}

Insecticide-treated bed nets and indoor residual spraying comprise the major control measures against Anopheles gambiae sl, the dominant vector in subSaharan Africa. The primary site of contact with insecticide is through the mosquitoes' legs, which represents the first barrier insecticides have to bypass to reach their neuronal targets. Proteomic changes and leg cuticle modifications have been associated with insecticide resistance that may reduce the rate of penetration of insecticides. Here, we performed a multiple transcriptomic analyses focusing on An. coluzzii legs.

\section{Results}

Firstly, leg-specific enrichment analysis identified 359 genes including the pyrethroid-binder SAP2 and 2 other chemosensory proteins, along with 4 ABCG transporters previously shown to be leg enriched. Enrichment gene families included those involved in detecting chemical stimuli including gustatory and ionotropic receptors and genes implicated in hydrocarbonsynthesis.

Subsequently, we compared transcript expression in the legs of a highly resistant strain (VK7-HR) to both a strain with very similar genetic background which has reverted to susceptibility after several generations without insecticide pressure (VK7-LR) and a lab susceptible population. 232 differentially expressed genes (73 up-regulated and 159 down-regulated) were identified in the resistant strain when compared to the two susceptible counterparts, indicating an over-expression of phase I detoxification enzymes 
and cuticular proteins, with decrease in hormone-related metabolic processes in legs from the insecticide resistant population.

Finally, we analysed the short-term effect of pyrethroid exposure on An. coluzzii legs, comparing 1hour-deltamethrin-exposed (VK7-IN) to unexposed (VK7HR) leg transcriptomes and identified 348 up-regulated genes including those encoding for GPCRs, ABC transporters, odorant-binding proteins and members of the divergent salivary gland protein family.

\section{Conclusions}

The data on An. coluzzii leg-specific transcriptome provides valuable insights into the first line of defense in pyrethroid resistant and short-term deltamethrin-exposed mosquitoes. Our results suggest that xenobiotic detoxification is likely occurring in legs, while the enrichment of sensory proteins, ABCG transporters and cuticular genes is also evident. Constitutive resistance is primarily associated with elevated levels of detoxification and cuticular genes, while short-term insecticide-induced tolerance is linked with overexpression of transporters, GPCRs and GPCR-related genes, sensory/binding and salivary gland proteins.

Keywords: Anopheles coluzzii, legs, constitutive insecticide resistance, shortterm induction, deltamethrin, transcriptomics

\section{Background}

Malaria continues to claim more than 400,000 lives each year, causing a severe global health problem, with more than $90 \%$ of cases and deaths occurring in Africa (WHO, 2019). Infection prevalence and case incidence have been 
remarkably reduced since 2000 , primarily through the use of insecticidetreated bed nets (ITNs) [1]. However, all bed nets currently distributed contain the pyrethroid class of insecticide [2]. As a result, malaria vectors have developed dramatic levels of resistance, which is a major threat for malaria control, especially in countries encountering the highest malaria burden [3, 4]. Analysis of molecular mechanisms underlying insecticide resistance have identified: i) mutations in the target site of the insecticide that reduce binding affinity [5], ii) behavioral avoidance [6] iii) cuticle alterations which lower the rate of insecticide penetration $[4,7]$ and iv) enhanced metabolism and/or sequestration of insecticides through overexpression of detoxification enzymes and other proteins, typically expressed constitutively but also upon induction [8]. Genes with direct roles in either metabolism or binding of insecticides include cytochrome P450s, glutathione S-transferases (GSTs), carboxlyesterases (CEEs) and the chemosensory protein SAP2 [9-13]. An enrichment in the transcription of detoxification gene transcripts has been observed in the midgut and Malpighian tubules of An. gambiae [4]; however, this study included limited numbers of tissues and resistance associated cytochrome $\mathrm{P} 45 \mathrm{Os}$ show a varied profile of tissue enrichment (including the head) (reviewed in [14]). Notably, midgut specific transgenic overexpression of the known pyrethroid metabolisers CYP6M2 or CYP6P3 did not induce the pyrethroid resistance phenotypes in susceptible An. gambiae [15] seen when these genes were ubiquitously expressed indicating that other tissues are also critical for detoxification.

Reduced penetration or cuticular resistance has been linked to pyrethroid resistance and has been correlated to thickening and/or altered composition of 
the cuticle in various insects [16]. This putative resistance mechanism is now being more widely reported in African malaria vectors [4], with several studies associating insecticide resistance with abundance of cuticular proteins [16-19]. Increasing resistance to pyrethroids in Anopheles populations across Africa has increased the impetus to develop new active ingredients active against these resistant populations. Reduced penetration could potentially confer cross resistance to new insecticide classes but there are critical gaps in our understanding of the uptake and subsequent clearance of the insecticide by mosquitoes both through constitutive and induced mechanisms; filling these gaps is important to develop resistance mitigation strategies and inform the design and formulation of new insecticides. The primary site of contact in the case of both ITNs and sprayed surfaces are the legs, and hence, the insecticides must first penetrate the leg cuticle in order to reach their target $[16,20]$. Dipteran legs are complex, poorly characterized structures compared to other tissues. Recent evidence generated from Drosophila single-cell transcriptomic atlas describes the existence of distinct cell types in legs including epidermal cells, muscles, neural cells (peripheral glia, sensory, gustatory and mechanosenosry neurons) and hemocytes along with cells of unannotated types [21]. Recent studies underline the importance of the legs in constitutive pyrethroid resistance both due to the thicker cuticle being enriched in chitin content and structural cuticular components $[3,17]$ and through sequestration mechanisms in resistant Anopheles legs mediated by the chemosensory protein $S A P 2$ [8]. It is not known if metabolic resistance is also taking place in mosquito legs; detoxification enzymes have previously been identified in the An. gambiae leg proteome [17], and the tick leg transcriptome contained a small number of 
P450s and GSTS, specifically in Haller's organ, which were postulate as odorant degrading enzymes [23]. In the recent transcriptomic dataset of $D$. melanogaster single-cell transcriptomic atlas, transcripts of several detoxification enzymes including cytochrome P450s, glutathione-Stransferases and UDP-glucoronotransferases have been identified in cell types constituting the legs [21], but their precise role remains elusive.

Although the majority of studies in resistant mosquitoes look at constitutive expression of transcripts of interest, a recent transcriptional time-course of sub-lethal pyrethroid exposure in whole An. coluzzii resistant mosquitoes demonstrated that over two thirds of transcripts change upon insecticide exposure. These changes were seen in a priori insecticide resistance candidates, such as detoxification genes, but the study also identified a decrease of oxidative phosphorylation and elevated DNA-repair [24]. Induction of metabolic resistance-related enzymes has also been observed post DDT exposure in Drosophila which induced the expression of Cyp6g1 and Cyp12d1 [25] and in permethrin-challenged house flies resulting in co-upregulation of three $\mathrm{P} 450$ genes in a time and dose-dependent manner [26]. Furthermore, transcription factors and pathways have been associated with transcriptional regulation of genes involved in response to xenobiotics such as cytochrome $\mathrm{P} 45 \mathrm{Os}$ or other detoxification enzymes. Such pathways include D. melanogaster Nrf2 (NE-E2related factor 2)[27, 28], An. gambiae Maf-S[4] and C. pipiens NYD-OP7 which belongs to the GPCR family that has been associated with deltamethrin resistance probably through NYD-OP7/PLC-mediated signaling of key P450s [29]. Additionally, oxidative stress elicited by insecticides has also been studied 
in various insects with a focus on hormonal-regulated triggering responses, involving neuropeptides such as insect adipokinetic hormones (AKH), which further implicated GPCR signaling [30]. Moreover, ATP-Binding-Cassette $(\mathrm{ABC})$ transporters, thought to participate in detoxification process in Phase o and Phase III [31, 32], have been found up-regulated post pyrethroid exposure in multiple studies [24, 33-36].

In addition to metabolic enzymes and changes to key signaling pathways, sensory proteins have been found to be induced in Anopheles resistant populations post-pyrethroid exposure $[8,24]$. These carrier proteins, found in the lymph of chemosensilla, are divided in insects in two different classes: Odorant-binding proteins (OBPs) and Chemosensory proteins (CSPs) [37]. Both are soluble ligand-binding proteins, known to detect and release chemical signals [38, 39], playing an important role in insect chemoreception by capturing and transporting hydrophobic chemicals from the environment to the chemosensory receptors [40, 41].

Here, we perform three distinct transcriptomic experiments identifying: (i) legspecific transcripts; (ii) transcripts involved in constitutive resistance in the legs of a pyrethroid resistant population and (iii) transcripts induced by pyrethroid exposure in the legs. We confirm that the pyrethroid binder SAP2 and other chemosensory proteins and transporters are leg-enriched, and demonstrate that legs from pyrethroid resistant mosquitoes have higher expression of phase I detoxification and cuticular genes with simultaneously decreased hormonerelated processes. Short-term insecticide-induced tolerance in the legs is associated with increased expression of transporters, GPCRs and GPCR-related genes, sensory/binding proteins and members of the divergent salivary gland 
protein family.

\section{Methods}

\section{Mosquito strains}

The mosquito strains used in the study belong to the An. gambiae species complex and were maintained in the laboratory under the same conditions for several generations before analysis. The standard insectary conditions for all strains were $27^{\circ} \mathrm{C}$ and $70-80 \%$ humidity under a 12-h: 12-h photoperiod with a 1-hour dawn:dusk cycle. The susceptible An. coluzzii N'Gousso strain (NG) collected from Cameroon is susceptible to almost all pyrethroid insecticides (some dieldrin resistance has been recorded) whilst the An. coluzzii strains from Burkina Faso (VK7 and Banfora) are highly resistant to pyrethroids and DDT $[11,42]$. Two colonies from VK7 were maintained in the laboratory: i) VK7-LR (lowly resistant) that almost completely lost resistance to deltamethrin, after several generations in the laboratory without pyrethroid selection, and ii) VK7-HR (highly resistant), a re-colonized population, highly resistant to deltamethrin (o\% mortality after $1 \mathrm{~h}$ exposure with deltamethrin diagnostic dose, Figure S1) which was maintained under deltamethrin selection pressure.

\section{Leg dissection, induction and RNA isolation}

Whole legs from 3-5 day old, non-blood fed female mosquitoes were dissected including all leg segments (coxa, trochanter, femur, tibia, and tarsus), using microdissection forceps (Figure S2). Four biological replicates each including 
legs from 20-30 female mosquitoes were prepared from each strain/condition. All collections were carried out between 1-3 hours after beginning of dawn period. For deltamethrin-induced sample preparation almost 100 mosquitoes from VK7-HR strain were exposed in $0.05 \%$ deltamethrin using WHO tubes and the survivors were let to recover for 1 hour (VK7-IN), after which all individuals were still alive. Legs were immediately dissected and put into RNA extraction buffer and proceeded to RNA extraction the same day (no storage of dissected tissues took place). For the preparation of the Banfora and N'Gousso whole body vs leg dataset, 3-5 day old females were snap frozen in biological triplicate; the Banfora legs included 24-hours post-deltamethrin exposure but as no difference in counts were seen to unexposed mosquitoes they were pooled into one 'Banfora' replicate. For whole bodies, 7 female mosquitoes were pooled and for leg extractions 30-50 mosquitoes were used. RNA extraction was done using the Arcturus PicoPure RNA Isolation Kit (Thermo Fischer Scientific), coupled with RNase-Free DNase Set (QIAGEN), following the manufacturer's instructions. Nanodrop spectrometer readings confirmed that submitted RNA quantity fell within ranges expected by sequencing centres.

\section{Preparation of Illumina libraries}

RNA-seq analysis took place in the Polo Genomics-Genetics-Biology (Polo GGB) facility using a NextSeq 550 Sequencer. The libraries were prepared in accordance with the Illumina TruSeq Stranded mRNA Sample Preparation Guide (Part \# 1000000040498 voo, Rev. E, Date October 2017) for Illumina Paired-End Indexed Sequencing. According to the Illumina mRNA libraries preparation protocol, poly-A mRNA in the tRNA samples were first purified using Illumina poly-T oligo-attached magnetic beads and two rounds of 
purification. During the second elution of the poly-A-RNA, the mRNA was also fragmented and primed with random hexamers for cDNA synthesis. Cleaved mRNAs were reverse transcribed into first strand cDNA using reverse transcriptase and random primers. The RNA template was then removed and a replacement strand synthesized to generate double-stranded cDNA. Following the standard protocol, after the first and second strand cDNA synthesis, a single "A" nucleotide is added to the 3' ends of the blunt fragments, and Illumina indexing adapters were ligated. Finally, cDNA fragments that have adapter molecules on both ends underwent 15 cycles of PCR to amplify the amount of prepared material. The resulting libraries were validated using the Fragment Analyzer to check size distribution. Concentration of library samples was defined on the basis of the Qubit ${ }^{\circledR}$ 3.0 Fluorometer quantification and average library size. Indexed DNA libraries were normalized to $4 \mathrm{nM}$ and then pooled in equal volumes. The pool was loaded at a concentration of $1.1 \mathrm{pM}$ onto an Illumina NextSeq 550 Flowcell High Output, with 1\%of Phix control. The samples were then sequenced using the Illumina chemistry V2.5, 2x75bp paired end run.

\section{Transcriptomic analysis}

The raw RNAseq reads from all four strains were mapped on the reference $A n$. gambiae PEST genome [43] (AgamP4.12) using hisat2 [44]. Next, expression was quantified at the gene level by using featureCounts [45] and the differential expression analyses were performed with EdgeR [46] for the VK7 experiments whilst limma and DREAM were used to identify leg-specific expression. For VK7, normalized expression values for all genes, namely Counts Per Million (CPM) and Transcripts Per Million (TPM), were computed using the EdgeR 
library [46], and custom perl scripts, respectively. Principal Component Analysis (PCA) was carried out using the TPM values, while the PCA plot was plotted with custom R scripts and the calibrate R library [47]. For discovery of transcripts showing leg specific expression, filterByExpr was used to remove genes with low counts as described, DREAM was then used to fit a linear mixed model taking into account both the population and the leg compared to whole organism whilst reducing false positive rate. For each analysis, a logFC cut off of $>|2|$ and adjusted $\mathrm{p}<0.01$ was applied for downstream analysis.

For subsequent analysis, venn diagrams were constructed using the VennDiagram R package [48], while visualization of the Gene Ontology (GO) enrichment results was implemented with custom R scripts, which make use of the ggplot2 R package [49]. Heatmaps were generated using the heatmap.2 function, which is part of the gplots R package [50]. Differentially expressed genes were searched for enriched functions based on their associated Gene Ontology (GO) terms. More specifically, g:Profiler [51] was used to perform functional enrichment analyses and find significantly over-represented GO terms in the differentially expressed gene sets, compared to the A. gambiae PEST reference genome.

\section{Phylogeny Reconstruction}

Multiple sequence alignment was performed with Mafft v7.310 [52] using the default parameters. The produced alignments were automatically trimmed using trimAl [53] and a custom Bash script was used to convert the trimmed alignments to a phylip format file. Finally, the phylogenetic tree was built under 
the maximum likelihood optimality criterion using RaxML 8.2.11 [54]. The phylogenetic tree was midpoint-rooted using FigTree 1 (available at: http://tree.bio.ed.ac.uk/software/figtree/) and visualization of the tree was performed using Evolview v3 [55].

\section{Results and Discussion}

\section{Transcriptome data quality}

We performed an RNAseq-based leg transcriptomic profiling of the An. coluzzii strains and the induced state (VK7-IN), generating a total of >968 million Illumina reads. Before implementing further investigation, a Principal Component Analysis (PCA) was performed to assess the quality of the replicates, using the transcription levels of all genes (Figure $\mathrm{S}_{3}$ and $\mathrm{S} 4$ ). The results of this analysis showed that most of the biological replicates from each strain clustered together and separately from the replicates of the other strains. However, one replicate from each of the N'Gousso (lab strain, fully susceptible), VK7-HR (highly resistant) and VK7-IN (deltamethrin-induced VK7-HR) samples did not cluster as expected. As a result, they were excluded in order to improve the reliability of downstream analyses (Figure S4).

\section{Leg-specific transcripts}

359 genes are enriched in the leg compared to the whole body (Table S1) with a striking number of genes related to a sensory function (Figure $1 \mathrm{~A}$ ); this may be unsurprising given the role of the legs in sensing the environment (Figure $\mathrm{S}_{5}$ ). Indeed, taste receptor activity (GO:0008527), detection of chemical stimulus 
(GO:0050912) and sensory perception of taste (GO:0050916) are significantly enriched. Interestingly, the most highly enriched terms relate to cilium organization (GO:0044782), cilium (GO:0005929) and phosphatidylinositol bisphosphate binding (GO:1902936) further indicating the legs are important in signaling (Figure S5). Cilia are known to be present in insect legs, as well as other organs (mouthparts antennae and wings), comprising the distal tips of type I sensory neuron dendrites of sensilla [56].

\section{Detoxification Genes}

15 genes from detoxification families are significantly enriched in the leg compared to the whole body (Figure 1B), of these 4 are cytochrome P450s (CYP4D17, CYP325H1, CYP9M2, CYP9L3) and COEs (COEBE3C, COE10O, OEAE3D, COEJHE1E) and 7 are ABC transporters. ABCG11, G19 and G2O have been previously shown to be enriched in the legs [57] and are thought to be involved in transporting of lipids to the mosquito cuticle as seen in $T$. castaneum [58]. Furthermore, these genes have previously been shown to be up-regulated in multiple insecticide resistant populations [59], hinting at a potential role in epicuticular thickening, via enhanced lipid transport/deposition.

\section{Cuticular Proteins}

11 cuticular proteins appear to be extremely leg specific (Figure 1C), with a range of $\mathrm{o}$ to 100 reads aligned in the whole body to 500-200o reads in the legs. Of these, CPLCG8 and CPR118, CPR73 have no reads in the whole body, whilst CPR1, CPR112, CPR115, CPR116, CPR119, CPR143 and CPR146 show read counts of $\sim 10$ in the whole body. Cuticle accounts for a large proportion of the leg and is composed of chitin, cuticular proteins and lipids [6o]. In general 
cuticle is synthesized by epidermal cells during every molting cycle [61], thus transcription of such genes in this tissue could be attributed to epidermal cells found underneath the cuticular layers.

LC-MS/MS studies to examine CPs of adult An. gambiae, including legs, have identified very few CPs restricted to only one structure [62-64]. Specifically for legs peptides for CPR139 (not present in our dataset) were restricted to this tissue, while CPR73, present in our leg-specific dataset was identified in legs and eye lens protein extracts [62]. In the same work peptides for CPR115, CPR118, CPR119, and CPR146 were identified in legs but also in different adult tissues and developmental stages while CPR1, CPR116 and CPR143 were identified in adult structures other than legs [62]. It has to be noted though that CPs form sequence clusters with almost identical sequences and hence their identification is carried out based on shared and few or no unique peptides, complicating the assignment of proteins to a single structure. Additionally, few CPs are restricted to a single structure or stage, indicating construction of morphologically different structures with almost the same CPs [64]. The identification of a small number of leg-specific transcripts here, is in general agreement with this observation from proteomics, whilst also supporting the classification of some CPs specifically in legs not previously identified there.

\section{Chemosensation}

The transcription of chemosensory-related transcripts in the legs is not surprising, as a plethora of studies support their expression in chemosensory sensilla of the appendages [65]. Indeed, cells in D. melanogaster tarsi that expressed OBPs, perform leg-mediated chemosensation [66] and OBPs were enriched in tarsi transcriptome of Ae. aegypti [67]. This protein family among 
other (chemosensory proteins, odorant, gustatory and ionotropic receptors) are secreted by accessory cells surrounding olfactory receptor neurons and they accumulate in the sensilla lymphs [68]. In total, 25 genes belonging to these families are enriched in the legs, including the pyrethroid binder SAP2 (Figure 1D).
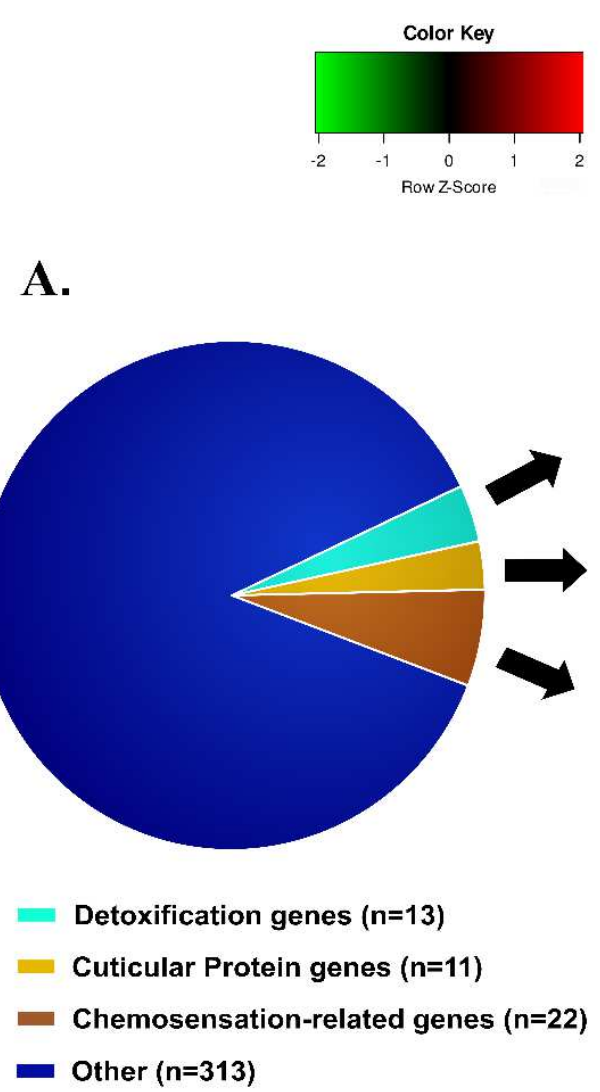

B.


D.

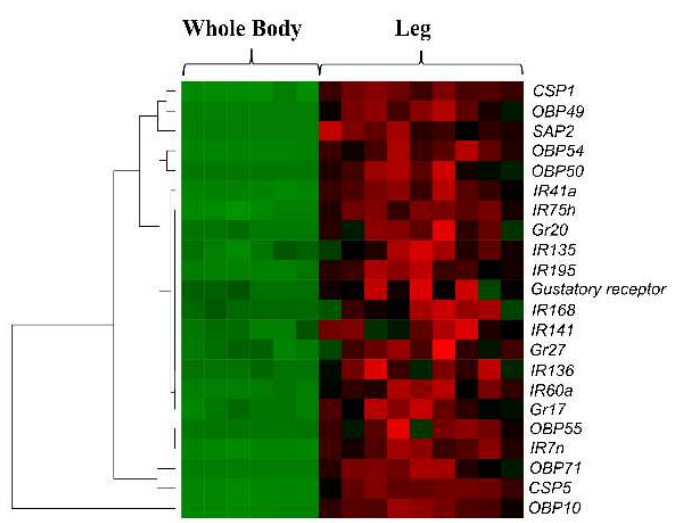

\section{Leg transcripts differentially expressed in resistant}

\section{Anopheles coluzzii}

In order to study constitutive resistance in the legs, we sequenced the leg transcriptomes of three different strains. The multi-resistant strain (VK7-HR) was compared to two susceptible strains, VK7-LR and N'Gousso (NG). VK7-LR 
originates from the VK7-HR population but was maintained without insecticide selection, resulting in a gradual loss of resistance. Contrarily, NG is lab susceptible strain, and therefore has a completely different genetic background to the two $\mathrm{VK}_{7}$ populations. In these comparisons we identified 542 differentially expressed genes in VK7-HR against NG (109 up-regulated, 433 down-regulated) and 415 differentially expressed genes in VK7-HR against VK7-LR (108 up-regulated, 307 down-regulated). Of these, 73 genes were upregulated and 159 genes were down-regulated in both comparisons and likely represent the genes contributing to the resistance phenotype (Figure 2, Table S2).

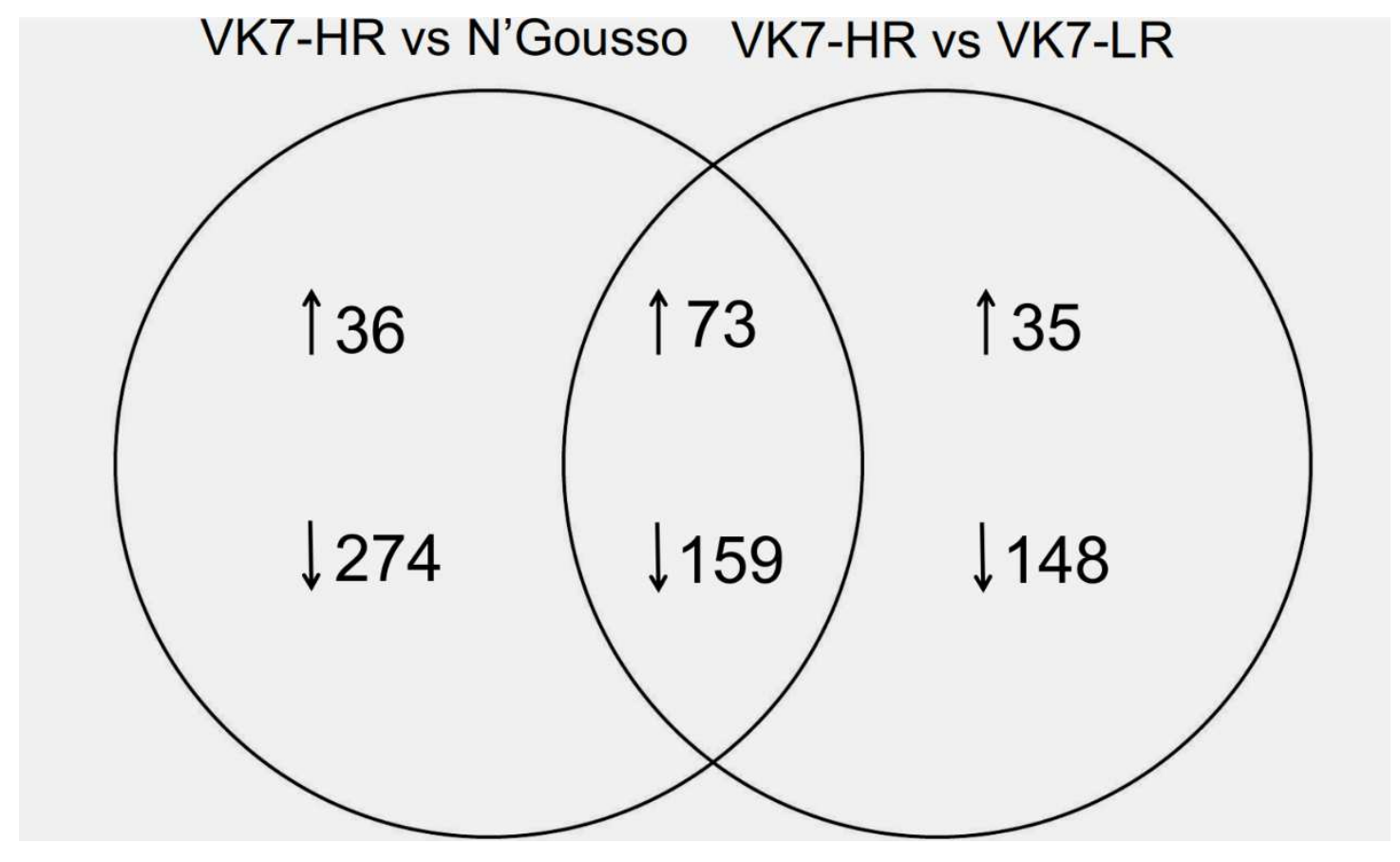

\section{Up-regulated transcripts in resistant Anopheles coluzzii}

Among the up-regulated genes there are two functional classes with previous links to insecticide resistance: detoxification enzymes and cuticular proteins (Figure 3A).

Detoxification enzymes 
Among the 73 up-regulated genes, there are 10 detoxification enzymes (13.70\%) including seven cytochrome P450s (CYP), two UDP-Glycosyltransferases (UGTs) and one carboxylesterase (CCE) (Figure 3B), with none of these being identified in the leg-specific transcriptome. Enrichment analysis identified the over-represented GO terms include iron ion binding (GO:0005506), oxidationreduction process (GO:0055114), monooxygenase activity (GO:0004497), heme binding (GO:0020037), tetrapyrrole binding (GO:0046906) and oxidoreductase activity and insecticide detoxification activity (GO:0016491) (Figure S6A), all of which are related to CYPs. Most of these GO terms (Figure S6A) have been recently associated with high levels of pyrethroid resistance in An. funestus [18], whilst $C Y P_{9} K_{1}$ and $C Y P 6 P 4$ have been previously implicated in pyrethroid resistance in Anopheles mosquitoes [69-71]. Furthermore, CYP6Z3 was previously associated with DDT, bendiocarb and pyrethroid resistance in An. gambiae, An. funestus and An. arabiensis populations [7276]. The remaining detoxification genes in the above list are functionally uncharacterized with regard to insecticide resistance. Detoxification enzymes have been previously identified in the leg-specific proteome [17]. However, none of these detoxification enzymes were up-regulated in the $\mathrm{VK}_{7}$ leg transcriptome of this study. The constitutive up-regulation of these genes supports the hypothesis that the legs are involved in immediate detoxification of insecticides and act as the first line of defence where at least partial detoxification of insecticides could occur. Consequently, this would lead to at least some deactivation of the toxic effects of the insecticide before it enters the insect body and exerts its toxic effects, or even protect the peripheral nerves that are present in Diptera legs [21], from pyrethroid toxicity. 
Cuticular proteins (CPs)

Cuticular thickening has been associated with insecticide resistance in Anopheles and Culex, as multiple CPs have been found up-regulated in resistant populations [18, 77, 79-82] and attenuation of expression of CPLCG5 leads to increase pyrethroid resistance in Culex . The current dataset further supports the hypothesis that cuticle remodeling plays a crucial role in insecticide resistance; 10 of the up-regulated genes (13.7\%) in VK7-HR encode for cuticular proteins (Figure 3C). These include members of the CPR family (CPR1, CPR6, CPR62, CPR111, CPR18 and CPR121), as well as the CPLCP (CPLCP1, CPLCP8) and the CPLCG (CPCLG3, CPLCG4) families (Figure 3C). Three of these genes, CPR1, CPR118 and CPLCP8 appear to be uniquely expressed in legs (see above).

A recent proteomic analysis of resistant versus susceptible mosquito legs revealed that cuticular proteins and specifically the CPR family were the most up-regulated proteins in resistant legs of the same resistant strain (VK7-HR) with the one used in this study [17] although only CPR62 and CPR121 are found up regulated in both the $\mathrm{VK} 7-\mathrm{HR}$ leg proteome and transcriptome comprised in this study [17]. CPLCG3 and CPLCG4 have been previously found localized in the leg endocuticle, potentially contributing to cuticle thickening and penetration rate of the insecticide [77]. CPCLP1 (AGAP013465; 19.5-86.5 fold) was among the most up-regulated genes against both susceptible strains, while the ortholog of $\mathrm{CPLCP}_{3}$ (AGAPoo8817; 8-fold) in D. melanogaster, Vajk-4, participates in cuticle barrier formation [78]. CPR111 was recently found to be over-expressed in multiple pyrethroid-resistant An. funestus strains [18]. 


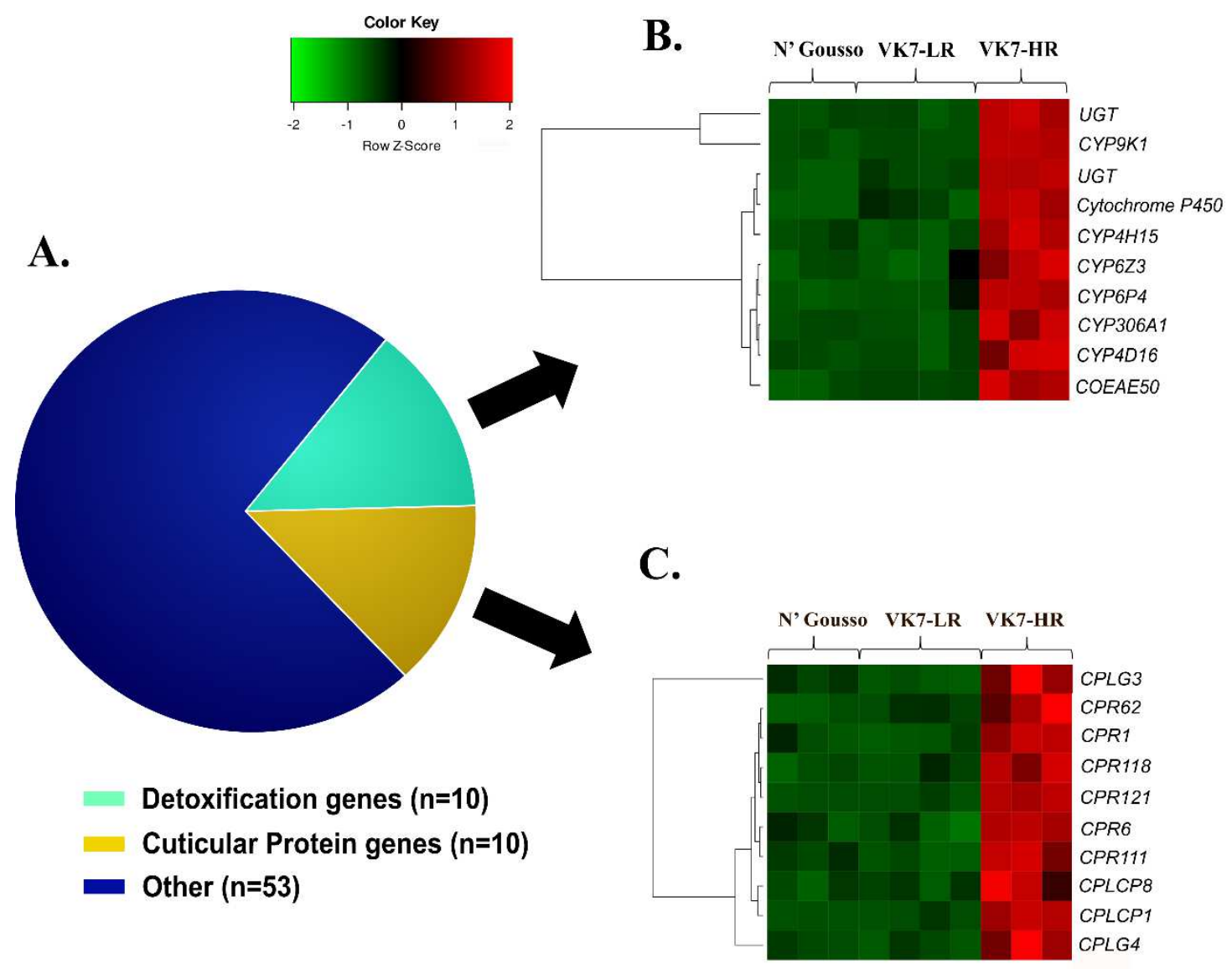

\section{Down-regulated genes in resistant Anopheles coluzzii}

Amongst the down-regulated genes (Figure 2, Table S2) the most noteworthy are odorant binding proteins and the ones related to hormone metabolism and salivary gland proteins (Figure 4A).

\section{Odorant binding proteins (OBPs)}

Several genes coding for OBPs (OBP1, OBP52, OBP26, OBP55, OBP53) (Figure 4B) and one gene coding for an odorant receptor were under-expressed in the resistant strain (Table S2, Figure S6B). Recent evidence derived from comparative proteomics supports the down-regulation of several OBPs in resistant legs. Models of An. gambiae OBPs suggest they can form hydrophobic channels enabling the transport of ligands, such as lipophilic insecticides [37, 83], and hence it is possible that down-regulation of OBPs could confer 
resistance due to decreased insecticide transport via these OBP-channels.

\section{Hormone-related genes}

Several hormone-related metabolic processes are under-represented in the VK7-HR resistant population (Figure 4C, Figure S6B). The corresponding GO terms include sterol metabolic process (GgO:0016125), steroid metabolic process (GO:0008202) and hormone activity (GO:0005179). More specifically, two sterol-o-transferases (AGAPo12216, AGAPo12217), two C-4 methylsterol oxidases (AGAPoo0946, AGAP002769), two insulin-like peptides (AGAPo10601, AGAP010604), adipokinetic hormone 2 (Adk2, AGAPoo2430) and Diuretic hormone 31 (DH31, AGAPoo1382) were down-regulated in the constitutive resistant state. Apart from the main hormonal centers found in the brain and prothoracic glands, the insect endocrine system also includes secretory cells in neural ganglia and the epidermis [30] . Thus, transcription of such insect hormones in the legs could be attributed to these cells. It is likely that the reduction of expression in these pathways reflects an attempt to decrease heavy metabolic cost imposed by stress to support other critical physiological functions taking place in the first line of xenobiotic metabolism. This is also in accordance with leg proteomics were metabolism-related proteins were the most down-regulated in the resistant legs compared to susceptible [17]. Intriguingly, among the down-regulated genes are four CYPs that belong to the CYP4 family (CYP4AA1, CYP49A1, CYP4J5 and CYP4J10). In insects, CYPs of this family are involved in metabolism of endogenous compounds such as pheromones and ecdysosteroids and other developmental hormone metabolism processes $[84,85]$, hence their downregulation is in agreement with the decrease in processes related to hormone metabolism. 
Salivary gland proteins (SGPs)

Among the constitutively down-regulated genes there were 13 genes coding for SGPs (Table S2). SGPs form a group of functionally and phylogenetically diverse protein families whose common feature is their expression in mosquito saliva [86]. This group includes proteins with enzymatic activities, implicated in blood feeding, anti-inflammatory, antihemostatic, vasodilatation and immunomodulatory responses [86, 87]. Identification of such transcripts in legs is surprising and their putative role there is unknown. Among the 13 downregulated SGP genes only D7r2 (AGAPoo8282) was previously identified in the VK7 leg proteome [15].

A.

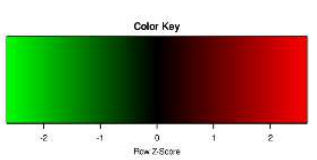

B.

N'Gousso VK7-LR VK7-HR
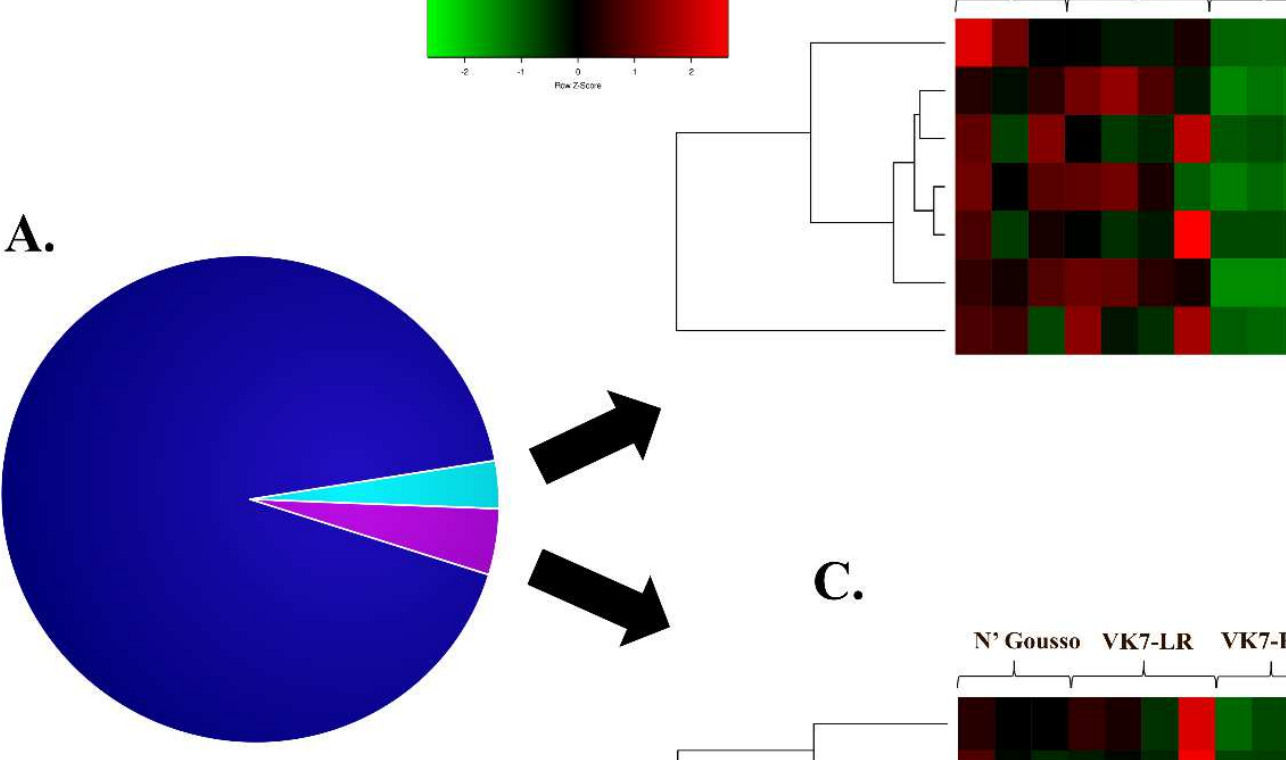

OBP55

OBP1

OBP52

OBP22

OBP53

$D 7 r 2$

Hormone-related genes $(n=5)$

Odorant Binding Protein genes $(n=7)$

Other $(n=147)$

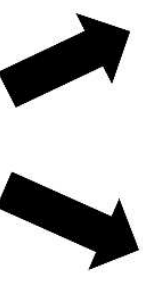

C.

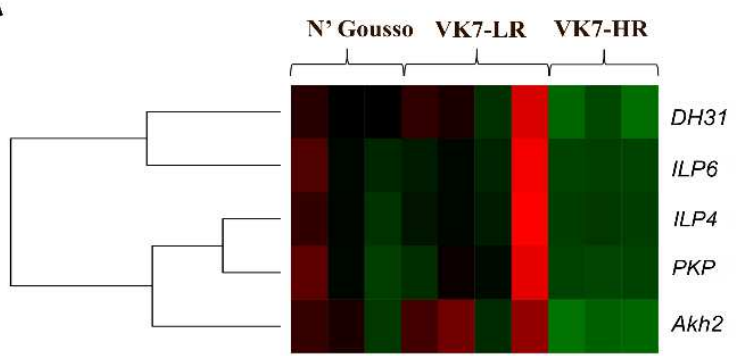

Leg transcripts regulated by short-term deltamethrin 


\section{induction}

To study genes whose expression is induced in the legs after exposure to pyrethroids, we exposed the VK7-HR strain to deltamethrin for one hour, followed by one hour recovery. Subsequently, the leg transcriptome of this induced strain (VK7-IN) was compared to that of the unexposed VK7-HR strain. Using the same strict statistical parameters $\left(\log _{2}|\mathrm{FC}|>2, \mathrm{FDR}<0.001\right)$, we identified 404 differentially expressed genes in VK7-IN compared to VK7HR (348 up-regulated, 56 down-regulated) (Table S3). The functional enrichment analysis of the up-regulated genes identified GO terms related to G protein-coupled receptor (GPCR) activity and drug catabolism (Figure S7). Interestingly, several genes coding for GPCRs, cytochrome P450s, ABC transporters and odorant binding proteins (OBPs), as well as proteins belonging to the divergent salivary gland protein family (SGPs), were upregulated after deltamethrin exposure (Figure $5 \mathrm{~A}$ ). On the contrary, the functional enrichment analysis of the down-regulated genes did not identify any overrepresented GO terms.

\section{Up-regulated leg transcripts upon deltamethrin induction}

Detoxification enzymes

Among the 348 up-regulated genes post-deltamethrin exposure there were eight detoxification genes (2.30\%): three CYPs (CYP6P3, CYP6M2 and CYP307A1), four $\mathrm{ABC}$ transporters and one carboxylesterase (Figure $5 \mathrm{~B}$ and Table S3). Interestingly, two of the three CYPs are known insecticide metabolisers (CYP6P3 and CYPM2) and were also induced in whole An. coluzzii mosquitoes after deltamethrin exposure, but also in different time points [24, 88]. Both CYP6P3 and CYP6M2 are capable of metabolizing all type I and type 
II pyrethroids used in vector control [89-91], in addition to bendiocarb, malathion, pirimiphos-methyl, Fenitrothion, DDT and pyriproxyfen [71] . None of the 8 detoxification enzymes overexpressed after deltamethrin exposure, including 3 p450s (CYP6M2, CYP6P3, CYP307A1) and one carboxylesterase (COEJHE2E) are leg-specific. CYP6M2 and CYP6P3 are up-regulated after 1 hour deltamethrin induction in whole An. coluzzii [24].

The fact that $\mathrm{ABC}$ transporter genes were up-regulated upon deltamethrin exposure (Figure 5B) and not constitutively, is consistent with the hypothesis that detoxification of phase o and/or III may take place upon induction [32]. The identified genes belong to the $\operatorname{ABCC}(n=1), \operatorname{ABCE}(n=1)$ and ABCG $(n=2)$ subfamilies (Figure 5B). Interestingly, ABCG11 which is identified among the leg-specific genes, is also up-regulated upon deltamethrin exposure. ABCCs have been implicated in translocation of a range of substrates including drugs, exogenous compounds and their glutathione conjugates. ABCGs facilitate lipid, sterol and drug transport, while ABCEs comprise a highly conserved family known to participate in translational control and mRNA transport [31]. Of note, eight of the An. gambiae ABCGs are enriched in legs, most probably transporting lipids to the cuticle [57]. Among the over-expressed ABC transporter genes in $\mathrm{VK} 7-\mathrm{IN}$ legs, $A B C C 2$ was recently found to be overexpressed in An. stephensi after 6- and 12-hr deltamethrin exposure [92], while post permethrin exposure ABCG4 of An. stephensi was over-expressed [36]. 1hour induction has also been studied in respect to $\mathrm{ABC}$ transporter expression in whole An. stephensi with ABCB and ABCG members being induced [93]. Additionally, a subset of An. gambiae sl ABC transporters (ABCC, ABCB, 
ABCG) were induced upon early and/or late permethrin exposure timepoints [24, 94] in whole An. gambiae sl also evident in An. stephensi [34].

\section{GPCR-mediated signaling}

The transcriptomic analysis identified seven up-regulated GPCR genes, six of which code for opsins (Figure $5 \mathrm{C}$ ). In particular, four of the six LW-sensitive and the SW-sensitive and UV-sensitive opsin genes were up-regulated after deltamethrin exposure, thus supporting the opsin-related functional enrichment (Figure S7).

The genome of An. gambiae contains 11 opsin genes, six of which belong to the Long Wavelength (LW)-sensitive family, one in each of the Short Wavelength (SW)-sensitive, Ultraviolet (UV)-sensitive and Rh7-like opsin families, and two are characterized as non-visual pteropsins [95]. In particular, four of the six LW-sensitive, and the SW-sensitive and UV-sensitive opsin genes were upregulated after deltamethrin exposure (Table S3). Opsins are sensory GPCRs with a well-characterized role in sensing light and regulating downstream signaling pathways in insects [96]. Additionally, recent studies in Drosophila provide evidence suggesting several light-independent roles, thus establishing opsins as polymodal sensors with a wide array of cellular and physiological functions [96]. A recent study demonstrated that an opsin, NYD-OP7 [97] leads to deltamethrin resistance in C. pipiens pallens by regulating the expression of several cytochrome P450 genes through a phospholipase C (PLC)-mediated signaling pathway [29]. Knockdown of the NYD-OP7 gene repressed the expression and the enzymatic activity of PLC, thus leading to reduced expression of downstream cytochrome $\mathrm{P} 450$ genes and increased susceptibility to deltamethrin[29]. Interestingly, among the six up-regulated opsin genes in 
VK7-HR legs after deltamethrin exposure (Figure 5C), there are three genes (GPROP1, GPROP3 and GPROP4) that belong to the expanded LW-sensitive opsin family [95] and form a sister clade to that containing NYD-OP7 in $C$. pipiens pallens (Figure S8). Two of these genes, GRPOP1 and GRPOP3, were also found to be over-expressed in a previous study that characterized the transcriptomic profile of the An. coluzzi VK multi-resistant populations [12].

Two arrestin genes, arrestin-1 (AGAPoo6263) and ARR2 (AGAP010134), were over-expressed after deltamethrin exposure (Table S3). Arrestins are small proteins that interact with GPCRs and regulate their activity [98]. Expression of Arrestin-1 has been previously reported in the olfactory organs (antennae, palps, proboscis) of An. gambiae and D. melanogaster, thus demonstrating that arrestin expression is not limited to photoreceptors [99]. Further, as olfaction is also present in the appendages, it is plausible that arrestins could also mediate such functions there. Both arrestins and GPCRs were found to be expressed in tick legs, with suggested roles in chemoreception [23].

Here we hypothesize that GPCR-mediated pathways could orchestrate the initial response to the stress imposed by deltamethrin. Such responses could be related to enhanced metabolic detoxification, as it has been demonstrated in Culex quinquefasciatus [100-102] and Spodoptera frugiperda Sf9 cells where GPCR-regulated pathways resulted in $\mathrm{P} 450$-mediated resistance after permethrin exposure [100].

Apart from this hypothesis, the presence of some neuropeptides in our dataset could imply some other GPCR-stimulated responses. More specifically adipokinetic hormone $2(\mathrm{AKH} 2)$ and Diuretic hormone $31(\mathrm{DH} 31)$ are also induced upon short-term deltamethrin exposure. Concerning the former, the 
AKH proteins are neuropeptides that upon stress have been shown to trigger energy catabolic reaction in insects to gain energy and also to stimulate stress responses such as enhanced locomotion, immune responses [30, 103] and energy mobilization by stimulation of lipolysis of triacylglycerols [104, 105]. Interestingly, the upregulation of $\mathrm{AKH}$ transcripts is profound in several studies upon insecticide stress [103, 106]. Finally, Diuretic hormone $31(\mathrm{DH} 31)$, has been shown to interact with a class II G-protein-coupled receptor $[107,108]$ with implication in thermosensation, thermoregulation and sleep modulation [109].

Odorant binding proteins (OBPs) and salivary gland proteins (SGPs)

Ten genes coding for odorant binding proteins (OBPs) were up-regulated after exposure to deltamethrin (Figure 5D). Of these, only OBP55 was identified in the leg-specific dataset too. Generally, OBPs have an important role in insect chemoreception by capturing hydrophobic chemicals from the environment and transporting them to the chemosensory receptors [40, 41]. Insect chemosensory sensilla are also present in the legs, in addition to other $[65,110]$. The leg sensing role in insects is crucial for recognizing non-volatile chemical signals $[111,112]$ and it is mediated by many different protein families, including OBPs and chemosensory proteins (CSPs) [110].

Interestingly, pheromone/odorant binding proteins were found overtranscribed under insecticide selection pressure in An. gambiae [81]. In addition, a transcriptomic meta-analysis underlines the persistent presence of OBPs in insecticide resistance comparing to susceptible datasets [59] while recent data from the fruit fly also highlight increased transcription of several members of this protein family post treatment with sub-lethal concentrations 
of insecticides [113].

The crucial role of such chemosensory, ligand-binding proteins in insecticide resistance in An. gambiae, was recently demonstrated with SAP2, a member of the lipocalin subfamily of CSPs [24, 38]. More specifically, it was demonstrated that SAP2 binds deltamethrin with high affinity, and overexpression of SAP2 in susceptible mosquitoes led to increased deltamethrin resistance [8]. In addition, SAP2 expression was induced upon exposure to deltamethrin, whilst attenuating expression led to higher mortality to all pyrethroids [8].

Moreover, six D7 salivary gland proteins that belong to the insect odorant binding protein superfamily [114], were up-regulated in VK7-HR legs after deltamethrin exposure: four of these belong to the short-form D7 SGPs (D7r14), while the remaining two code for the long-form D7 SGPs (D7L1-2) [86].

There are several studies that implicate members of the D7 family with constitutive insecticide resistance $[17,115,116]$, but to our knowledge this is the first dataset that shows their up-regulation upon pyrethroid exposure. The inability to detect these transcripts could be due to the "diluting" effect of whole body sequencing; legs are a relatively small tissue and so relatively contribute a small amount of RNA to the total extraction.

Whole genome microarrays of bendiocarb-resistant An. gambiae species from Uganda demonstrated significant over-expression of the D7r2 and D7r 4 genes while prediction models reveal that binding of $D 7 r 4$ and bendiocarb simulates D7r4 binding with its known ligand, serotonin [115], implying a role of D7 SGPs in direct insecticide binding. However, it should be mentioned that D7r2 showed a sustained down-regulation 4 and 8 hours after deltamethrin exposure $[24]$. 
Apart from D7 SGPs, in total, 33 genes coding for SGPs were over-expressed in VK7-HR legs after deltamethrin exposure (Table S3) nine of which were among the 20 most up-regulated genes. Identification of SGP transcripts in An. coluzzii legs is an interesting finding as it shows that expression of this group of proteins is not salivary gland specific. Moreover, we also show that their expression is enhanced upon short-term deltamethrin induction. However, their putative role in legs and their contribution upon insecticide induction is unknown and requires further study.

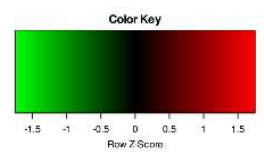

A.

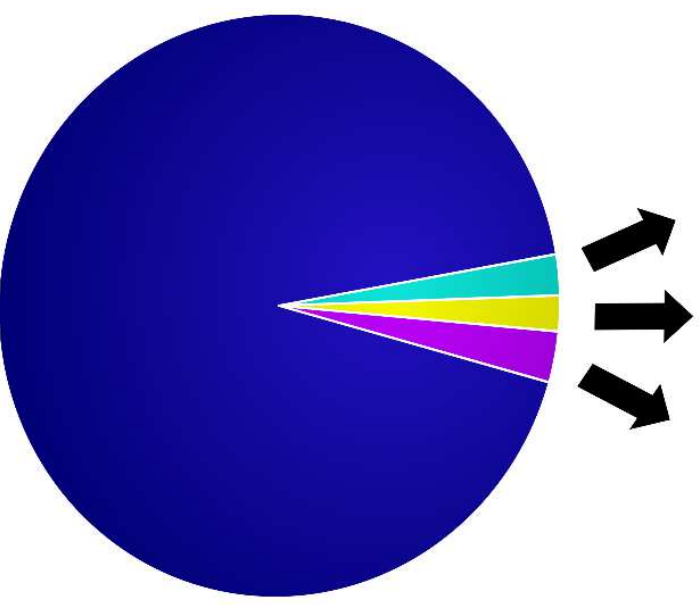

- Detoxification genes $(n=8)$

G-Protein Coupled Receptor genes $(n=7)$

- Odorant Binding Protein genes $(n=10)$

- Other $(n=323)$
B.

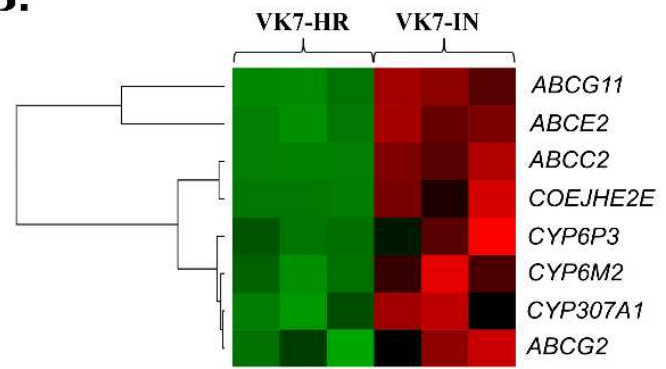

C.

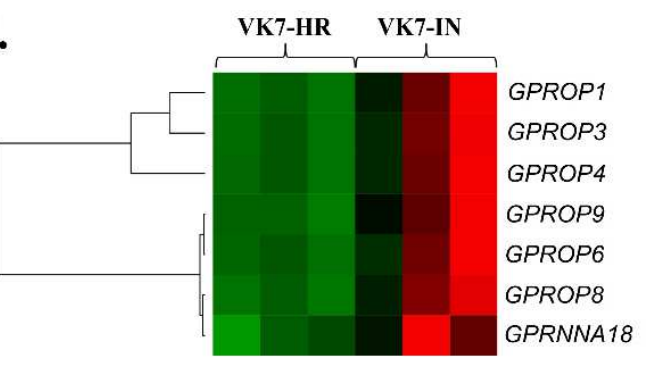

D.

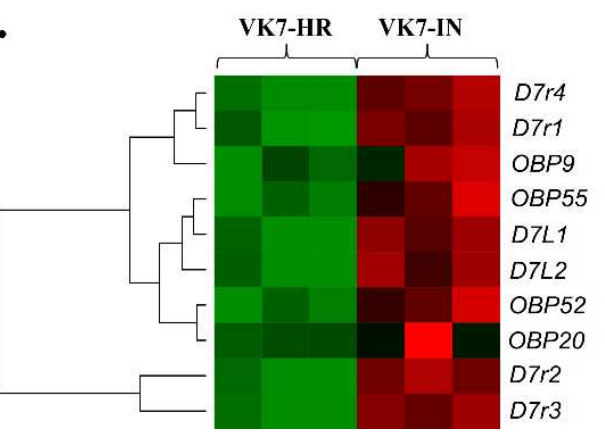

Down-regulated leg transcripts upon deltamethrin induction

Only 56 genes were under-expressed upon short term deltamethrin exposure, which accounts only for $13.8 \%$ of the total differentially expressed genes (Table S3). The functional enrichment analysis did not identify any over-represented 
GO terms in this subset. The most down-regulated genes after deltamethrin exposure was elongation of very long chain fatty acids protein 4 (AGAP010695), three genes encoding for cuticular proteins (CPR73 and CPLCG2, CPLCP8), two CYPs (CYP325C2, CYP325H1) and one ABC transporter (ABCG18). Among these, CPR73 is also a leg-specific gene, while CPLCP8 was up-regulated in constitutively resistant legs. Other studies also show down-regulation of detoxification family members in different time points post-pyrethroid exposure [24].

\section{Combined analysis of leg transcript datasets}

Overall this leg-specific transcriptomic dataset indicates that induction and constitutive resistant profile are divergent (Figure 6). Indicative is the fact that only three common up-regulated genes were found between the two states (constitutive and induced). Two of these encode for alpha-crystallins, previously implicated in pyrethroid resistance and long-term deltamethrin induction [59]. On the other hand, 68 genes that were down-regulated in the legs of constitutively resistant mosquitoes were up-regulated upon short-term deltamethrin induction (Table $\mathrm{S} 4$ ).

This opposite trend in constitutive and induced state is also reflected by the fact that $68,5 \%$ of the constitutively differentially expressed genes are downregulated, while this percentage is only $13.8 \%$ for deltamethrin exposed legs. In the former state, this is potentially indicative of an energy-saving mode compared to the more energy-costly profile of the latter stressful situation. 


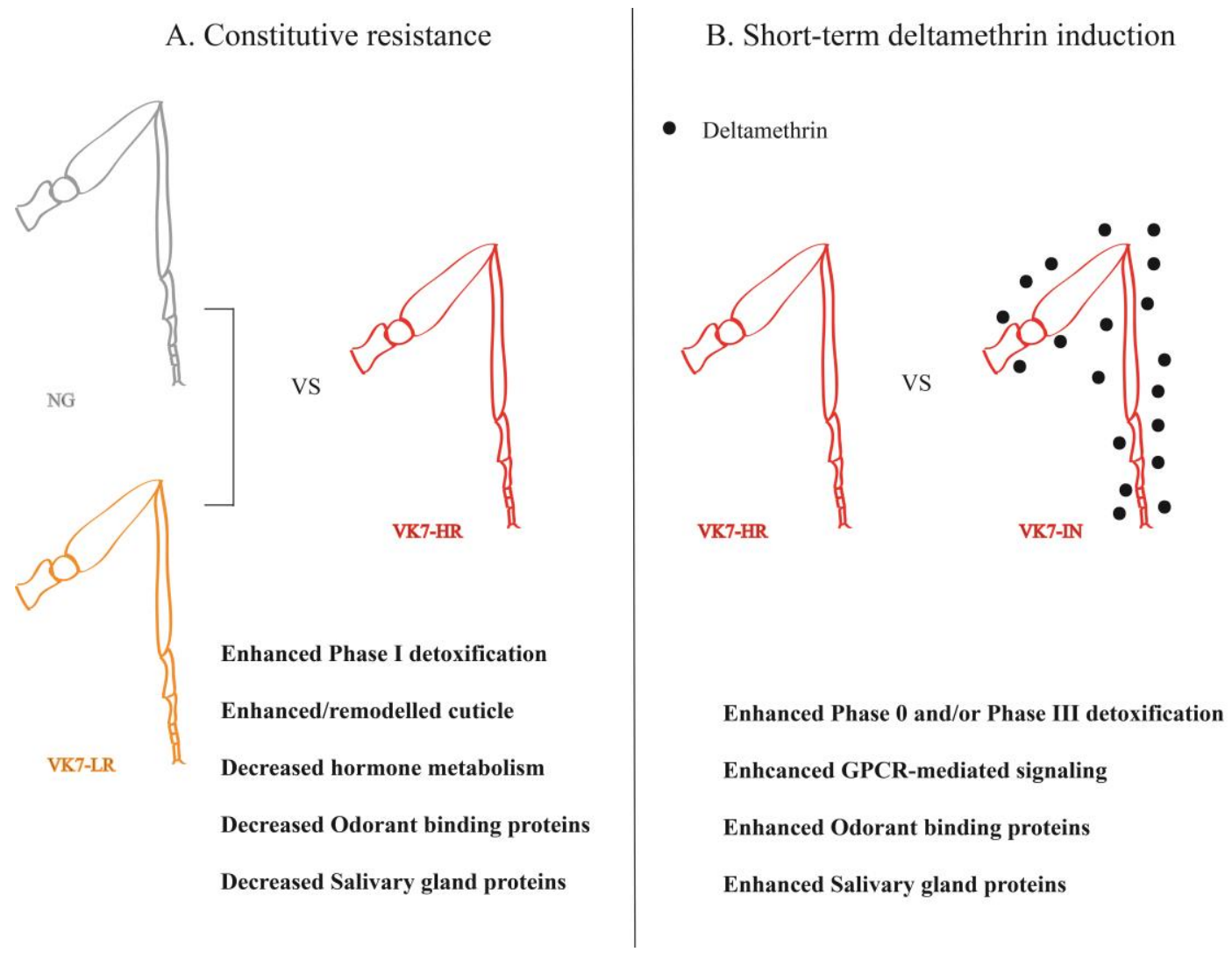

\section{Conclusions}

Overall, this study provides detailed analysis on the transcriptional profile of mosquito legs, describing the leg-specific transcriptome and both the differential expression in pyrethroid resistant legs and upon exposure to pyrethroid insecticides. Taken together, these data describe what is likely to be the first line of defense against vector control tools and suggests that metabolic detoxification is likely occurring in these tissues. Analyzing the transcriptome of only the legs, effectively removes the noise of the remaining body and avoids "diluting" the transcripts specifically expressed in this relatively small tissue. Leg specific expression is enriched in sensory related proteins, as expected given their role in chemosensation and transport; this includes SAP2 and several members of the ABCG family respectively. Eleven cuticular proteins show clear leg enrichment, with several of the transcripts showing low or no 
expression in the whole body. Further, our data suggest that constitutive resistance can be attributed at a degree at least to the transcription of detoxification genes and cuticular genes, with a simultaneous decrease in hormone-related metabolism. On the other hand, short-term insecticideinduced tolerance seems to be linked with increased transcription of transporters, GPCRs and GPCR-related genes, sensory/binding proteins and salivary gland proteins. Additionally, according to our findings GPCRmediated signaling has a leading role in leg induction, most likely via triggering the initial responses upon this stressing situation. Surprisingly, salivary gland proteins are highly expressed in the legs, down-regulated in the constitutive state and induced upon short-term deltamethrin exposure, given previous links with resistance, these proteins require further study.

\section{References}

1. Bhatt S, Weiss DJ, Cameron E, Bisanzio D, Mappin B, Dalrymple U, Battle KE, Moyes CL, Henry A, Eckhoff PA et al: The effect of malaria control on Plasmodium falciparum in Africa between 2000 and 2015. Nature 2015, 526(7572):207-211.

2. Cook J, Tomlinson S, Kleinschmidt I, Donnelly MJ, Akogbeto M, Adechoubou A, Massougbodji A, Okê-Sopoh M, Corbel V, Cornelie S et al: Implications of insecticide resistance for malaria vector control with long-lasting insecticidal nets: trends in pyrethroid resistance during a WHO-coordinated multi-country prospective study. Parasites \& Vectors 2018, 11(1):550.

3. Balabanidou V, Kampouraki A, MacLean M, Blomquist GJ, Tittiger C, Juárez MP, Mijailovsky SJ, Chalepakis G, Anthousi A, Lynd A et al: Cytochrome P450 associated with insecticide resistance catalyzes cuticular hydrocarbon production in Anopheles gambiae. Proc Natl Acad Sci U S A 2016, 113(33):92689273.

4. Ingham VA, Pignatelli P, Moore JD, Wagstaff S, Ranson H: The transcription factor Maf-S regulates metabolic resistance to insecticides in the malaria vector Anopheles gambiae. BMC genomics 2017, 18(1):669.

5. Hemingway J, Hawkes NJ, McCarroll L, Ranson H: The molecular basis of insecticide resistance in mosquitoes. Insect biochemistry and molecular biology 2004, 34(7):653-665.

6. Rivero A, Vézilier J, Weill M, Read AF, Gandon S: Insecticide control of vector- 
borne diseases: when is insecticide resistance a problem? PLoS Pathog 2010, 6(8):e1001000-e1001000.

7. Bass C, Jones CM: Mosquitoes boost body armor to resist insecticide attack. Proc Natl Acad Sci U S A 2016, 113(33):9145-9147.

8. Ingham VA, Anthousi A, Douris V, Harding NJ, Lycett G, Morris M, Vontas J, Ranson $\mathrm{H}$ : A sensory appendage protein protects malaria vectors from pyrethroids. Nature 2020, 577(7790):376-380.

9. Zoh DD, Ahoua Alou LP, Toure M, Pennetier C, Camara S, Traore DF, Koffi AA, Adja AM, Yapi A, Chandre F: The current insecticide resistance status of Anopheles gambiae (s.l.) (Culicidae) in rural and urban areas of Bouaké, Côte d'Ivoire. Parasit Vectors 2018, 11(1):118.

10. Koffi AA, Ahoua Alou LP, Adja MA, Chandre F, Pennetier C: Insecticide resistance status of Anopheles gambiae s.s population from M'Bé: a WHOPES-labelled experimental hut station, 10 years after the political crisis in Côte d'Ivoire. Malaria Journal 2013, 12(1):151.

11. Williams J, Flood L, Praulins G, Ingham VA, Morgan J, Lees RS, Ranson H: Characterisation of Anopheles strains used for laboratory screening of new vector control products. Parasites \& Vectors 2019, 12(1):522.

12. Kwiatkowska RM, Platt N, Poupardin R, Irving H, Dabire RK, Mitchell S, Jones CM, Diabaté A, Ranson H, Wondji CS: Dissecting the mechanisms responsible for the multiple insecticide resistance phenotype in Anopheles gambiae s.s., M form, from Vallée du Kou, Burkina Faso. Gene 2013, 519(1):98-106.

13. Edi CV, Djogbénou L, Jenkins AM, Regna K, Muskavitch MAT, Poupardin R, Jones CM, Essandoh J, Kétoh GK, Paine MJI et al: CYP6 P450 Enzymes and ACE-1 Duplication Produce Extreme and Multiple Insecticide Resistance in the Malaria Mosquito Anopheles gambiae. PLOS Genetics 2014, 10(3):e1004236.

14. Vontas J, Katsavou E, Mavridis K: Cytochrome P450-based metabolic insecticide resistance in Anopheles and Aedes mosquito vectors: Muddying the waters. Pestic Biochem Physiol 2020, 170:104666.

15. Adolfi A, Poulton B, Anthousi A, Macilwee S, Ranson H, Lycett GJ: Functional genetic validation of key genes conferring insecticide resistance in the major African malaria vector, Anopheles gambiae. Proc Natl Acad Sci U S A 2019, 116(51):25764-25772.

16. Balabanidou V, Grigoraki L, Vontas J: Insect cuticle: a critical determinant of insecticide resistance. Current Opinion in Insect Science 2018, 27:68-74.

17. Balabanidou V, Kefi M, Aivaliotis M, Koidou V, Girotti JR, Mijailovsky SJ, Juárez MP, Papadogiorgaki E, Chalepakis G, Kampouraki A et al: Mosquitoes cloak their legs to resist insecticides. Proceedings Biological sciences 2019, 286(1907):20191091.

18. Weedall GD, Mugenzi LMJ, Menze BD, Tchouakui M, Ibrahim SS, Amvongo-Adjia $\mathrm{N}$, Irving $\mathrm{H}$, Wondji MJ, Tchoupo M, Djouaka R et al: A cytochrome $\mathbf{P 4 5 0}$ allele confers pyrethroid resistance on a major African malaria vector, reducing insecticide-treated bednet efficacy. Sci Transl Med 2019, 11(484).

19. Simma EA, Dermauw W, Balabanidou V, Snoeck S, Bryon A, Clark RM, Yewhalaw D, Vontas J, Duchateau L, Van Leeuwen T: Genome-wide gene expression profiling reveals that cuticle alterations and $\mathbf{P 4 5 0}$ detoxification are associated with deltamethrin and DDT resistance in Anopheles arabiensis populations from Ethiopia. Pest Manag Sci 2019, 75(7):1808-1818.

20. Andriessen R, Snetselaar J, Suer RA, Osinga AJ, Deschietere J, Lyimo IN, Mnyone LL, Brooke BD, Ranson H, Knols BG et al: Electrostatic coating enhances bioavailability of insecticides and breaks pyrethroid resistance in mosquitoes. Proceedings of the National Academy of Sciences of the United States of America 2015, 112(39):12081-12086.

21. Li H, Janssens J, De Waegeneer M, Kolluru SS, Davie K, Gardeux V, Saelens W, David F, Brbić M, Leskovec J et al: Fly Cell Atlas: a single-cell transcriptomic 
atlas of the adult fruit fly. bioRxiv 2021:2021.2007.2004.451050.

22. Bingham G, Strode C, Tran L, Khoa PT, Jamet HP: Can piperonyl butoxide enhance the efficacy of pyrethroids against pyrethroid-resistant Aedes aegypti? Tropical Medicine \& International Health 2011, 16(4):492-500.

23. Carr AL, Mitchell RD, III, Dhammi A, Bissinger BW, Sonenshine DE, Roe RM: Tick Haller's Organ, a New Paradigm for Arthropod Olfaction: How Ticks Differ from Insects. Int J Mol Sci 2017, 18(7):1563.

24. Ingham VA, Brown F, Ranson $\mathrm{H}$ : Transcriptomic analysis reveals pronounced changes in gene expression due to sub-lethal pyrethroid exposure and ageing in insecticide resistance Anopheles coluzzii. BMC Genomics 2021, 22(1):337.

25. Festucci-Buselli RA, Carvalho-Dias AS, de Oliveira-Andrade M, Caixeta-Nunes C, Li HM, Stuart JJ, Muir W, Scharf ME, Pittendrigh BR: Expression of Cyp6g1 and Cyp12d1 in DDT resistant and susceptible strains of Drosophila melanogaster. Insect molecular biology 2005, 14(1):69-77.

26. Zhu F, Li T, Zhang L, Liu N: Co-up-regulation of three $\mathbf{P 4 5 0}$ genes in response to permethrin exposure in permethrin resistant house flies, Musca domestica. $B M C$ physiology 2008, 8:18.

27. Misra JR, Horner MA, Lam G, Thummel CS: Transcriptional regulation of xenobiotic detoxification in Drosophila. Genes \& development 2011, 25(17):17961806.

28. Shen G, Kong AN: Nrf2 plays an important role in coordinated regulation of Phase II drug metabolism enzymes and Phase III drug transporters. Biopharmaceutics \& drug disposition 2009, 30(7):345-355.

29. Zhou D, Duan B, Xu Y, Ma L, Shen B, Sun Y, Zhu C: NYD-OP7/PLC regulatory signaling pathway regulates deltamethrin resistance in Culex pipiens pallens (Diptera: Culicidae). Parasites \& Vectors 2018, 11(1):419.

30. Kodrík D, Bednářová A, Zemanová M, Krishnan N: Hormonal Regulation of Response to Oxidative Stress in Insects-An Update. Int J Mol Sci 2015, 16(10):25788-25816.

31. Dermauw W, Van Leeuwen $\mathrm{T}$ : The $\mathbf{A B C}$ gene family in arthropods: comparative genomics and role in insecticide transport and resistance. Insect Biochem $\mathrm{Mol}$ Biol 2014, 45:89-110.

32. Kennedy C, Tierney K: Xenobiotic Protection xenobiotic protection /Resistance Mechanisms in Organisms. In.; 2012: 12293-12314.

33. Mastrantonio V, Ferrari M, Negri A, Sturmo T, Favia G, Porretta D, Epis S, Urbanelli S: Insecticide Exposure Triggers a Modulated Expression of ABC Transporter Genes in Larvae of Anopheles gambiae s.s. Insects 2019, 10(3).

34. De Marco L, Sassera D, Epis S, Mastrantonio V, Ferrari M, Ricci I, Comandatore F, Bandi C, Porretta D, Urbanelli S: The choreography of the chemical defensome response to insecticide stress: insights into the Anopheles stephensi transcriptome using RNA-Seq. Scientific reports 2017, 7:41312-41312.

35. Epis S, Porretta D, Mastrantonio V, Urbanelli S, Sassera D, De Marco L, Mereghetti $\mathrm{V}$, Montagna M, Ricci I, Favia G et al: Temporal dynamics of the ABC transporter response to insecticide treatment: insights from the malaria vector Anopheles stephensi. Scientific reports 2014, 4:7435-7435.

36. Epis S, Porretta D, Mastrantonio V, Comandatore F, Sassera D, Rossi P, Cafarchia C, Otranto D, Favia G, Genchi $\mathrm{C}$ et al: ABC transporters are involved in defense against permethrin insecticide in the malaria vector Anopheles stephensi. Parasit Vectors 2014, 7:349.

37. Pelosi P, Zhou JJ, Ban LP, Calvello M: Soluble proteins in insect chemical communication. Cellular and molecular life sciences : CMLS 2006, 63(14):16581676.

38. Pelosi P, Iovinella I, Felicioli A, Dani FR: Soluble proteins of chemical communication: an overview across arthropods. Frontiers in Physiology 2014, 5(320). 
39. Iovinella I, Bozza F, Caputo B, Della Torre A, Pelosi P: Ligand-binding study of Anopheles gambiae chemosensory proteins. Chemical senses 2013, 38(5):409-419.

40. Gu SH, Wang SY, Zhang XY, Ji P, Liu JT, Wang GR, Wu KM, Guo YY, Zhou JJ, Zhang YJ: Functional characterizations of chemosensory proteins of the alfalfa plant bug Adelphocoris lineolatus indicate their involvement in host recognition. PloS one 2012, 7(8):e42871.

41. Bautista MA, Bhandary B, Wijeratne AJ, Michel AP, Hoy CW, Mittapalli O: Evidence for trade-offs in detoxification and chemosensation gene signatures in Plutella xylostella. Pest management science 2015, 71(3):423-432.

42. Namountougou M, Simard F, Baldet T, Diabaté A, Ouédraogo JB, Martin T, Dabiré RK: Multiple Insecticide Resistance in Anopheles gambiae s.l. Populations from Burkina Faso, West Africa. PLOS ONE 2012, 7(11):e48412.

43. Sharakhova MV, Hammond MP, Lobo NF, Krzywinski J, Unger MF, Hillenmeyer ME, Bruggner RV, Birney E, Collins FH: Update of the Anopheles gambiae PEST genome assembly. Genome biology 2007, 8(1):R5.

44. Kim D, Paggi JM, Park C, Bennett C, Salzberg SL: Graph-based genome alignment and genotyping with HISAT2 and HISAT-genotype. Nature Biotechnology 2019, 37(8):907-915.

45. Liao Y, Smyth GK, Shi W: featureCounts: an efficient general purpose program for assigning sequence reads to genomic features. Bioinformatics (Oxford, England) 2014, 30(7):923-930.

46. Robinson MD, Oshlack A: A scaling normalization method for differential expression analysis of RNA-seq data. Genome Biology 2010, 11(3):R25.

47. Graffelman J: Calibrate: calibration of scatterplot and biplot axes. $R$ package version 2019, 1(2).

48. Chen H, Boutros PC: VennDiagram: a package for the generation of highlycustomizable Venn and Euler diagrams in R. BMC Bioinformatics 2011, 12(1):35.

49. Wickham H: ggplot2 Elegant Graphics for Data Analysis; 2016.

50. Warnes G, Bolker B, Lumley T: gtools: Various R Programming Tools. R package version 3.5. 0. In.: Von https://CRAN. R-project. org/package= gtools abgerufen; 2015.

51. Reimand J, Arak T, Adler P, Kolberg L, Reisberg S, Peterson H, Vilo J: g:Profiler-a web server for functional interpretation of gene lists (2016 update). Nucleic acids research 2016, 44(W1):W83-89.

52. Katoh K, Standley DM: MAFFT Multiple Sequence Alignment Software Version 7: Improvements in Performance and Usability. Molecular Biology and Evolution 2013, 30(4):772-780.

53. Capella-Gutiérrez S, Silla-Martínez JM, Gabaldón T: trimAl: a tool for automated alignment trimming in large-scale phylogenetic analyses. Bioinformatics 2009, 25(15):1972-1973.

54. Stamatakis A: RAxML version 8: a tool for phylogenetic analysis and postanalysis of large phylogenies. Bioinformatics 2014, 30(9):1312-1313.

55. Subramanian B, Gao S, Lercher M, Hu S, Chen W-H: Evolview v3: a webserver for visualization, annotation, and management of phylogenetic trees. Nucleic acids research 2019, 47.

56. Kernan MJ: Mechanotransduction and auditory transduction in Drosophila. Pflügers Archiv - European Journal of Physiology 2007, 454(5):703-720.

57. Pignatelli P, Ingham VA, Balabanidou V, Vontas J, Lycett G, Ranson H: The Anopheles gambiae ATP-binding cassette transporter family: phylogenetic analysis and tissue localization provide clues on function and role in insecticide resistance. Insect molecular biology 2018, 27(1):110-122.

58. Broehan G, Kroeger T, Lorenzen M, Merzendorfer H: Functional analysis of the ATP-binding cassette (ABC) transporter gene family of Tribolium castaneum. BMC genomics 2013, 14:6.

59. Ingham VA, Wagstaff $\mathrm{S}$, Ranson $\mathrm{H}$ : Transcriptomic meta-signatures identified in 
Anopheles gambiae populations reveal previously undetected insecticide resistance mechanisms. Nature communications 2018, 9(1):5282.

60. Moussian B: Recent advances in understanding mechanisms of insect cuticle differentiation. Insect biochemistry and molecular biology 2010, 40(5):363-375.

61. Charles J-P: The regulation of expression of insect cuticle protein genes. Insect biochemistry and molecular biology 2010, 40:205-213.

62. Zhou Y, Badgett MJ, Orlando R, Willis JH: Proteomics reveals localization of cuticular proteins in Anopheles gambiae. Insect biochemistry and molecular biology 2019, 104:91-105.

63. Zhou Y, Badgett MJ, Billard L, Bowen JH, Orlando R, Willis JH: Properties of the cuticular proteins of Anopheles gambiae as revealed by serial extraction of adults. PloS one 2017, 12(4):e0175423.

64. Zhou Y, Badgett MJ, Bowen JH, Vannini L, Orlando R, Willis JH: Distribution of cuticular proteins in different structures of adult Anopheles gambiae. Insect biochemistry and molecular biology 2016, 75:45-57.

65. Rihani K, Ferveur J-F, Briand L: The 40-Year Mystery of Insect Odorant-Binding Proteins. Biomolecules 2021, 11(4):509.

66. Galindo K, Smith DP: A large family of divergent Drosophila odorant-binding proteins expressed in gustatory and olfactory sensilla. Genetics 2001, 159(3):1059-1072.

67. Sparks JT, Bohbot JD, Dickens JC: The genetics of chemoreception in the labella and tarsi of Aedes aegypti. Insect Biochemistry and Molecular Biology 2014, 48:816.

68. He X, He ZB, Zhang YJ, Zhou Y, Xian PJ, Qiao L, Chen B: Genome-wide identification and characterization of odorant-binding protein (OBP) genes in the malaria vector Anopheles sinensis (Diptera: Culicidae). Insect science 2016, 23(3):366-376.

69. Vontas J, Grigoraki L, Morgan J, Tsakireli D, Fuseini G, Segura L, Niemczura de Carvalho J, Nguema R, Weetman D, Slotman MA et al: Rapid selection of a pyrethroid metabolic enzyme CYP9K1 by operational malaria control activities. Proceedings of the National Academy of Sciences of the United States of America 2018, 115(18):4619-4624.

70. Ibrahim SS, Riveron JM, Stott R, Irving H, Wondji CS: The cytochrome P450 CYP6P4 is responsible for the high pyrethroid resistance in knockdown resistance-free Anopheles arabiensis. Insect Biochem Mol Biol 2016, 68:23-32.

71. Yunta C, Hemmings K, Stevenson B, Koekemoer LL, Matambo T, Pignatelli P, Voice M, Nász S, Paine MJI: Cross-resistance profiles of malaria mosquito P450s associated with pyrethroid resistance against $\mathrm{WHO}$ insecticides. Pesticide biochemistry and physiology 2019, 161:61-67.

72. Antonio-Nkondjio C, Poupardin R, Tene BF, Kopya E, Costantini C, AwonoAmbene P, Wondji CS: Investigation of mechanisms of bendiocarb resistance in Anopheles gambiae populations from the city of Yaoundé, Cameroon. Malaria Journal 2016, 15(1):424.

73. Müller P, Donnelly MJ, Ranson H: Transcription profiling of a recently colonised pyrethroid resistant Anopheles gambiae strain from Ghana. BMC genomics 2007, 8:36.

74. Müller P, Warr E, Stevenson BJ, Pignatelli PM, Morgan JC, Steven A, Yawson AE, Mitchell SN, Ranson H, Hemingway J et al: Field-caught permethrin-resistant Anopheles gambiae overexpress CYP6P3, a P450 that metabolises pyrethroids. PLoS genetics 2008, 4(11):e1000286.

75. Nardini L, Christian RN, Coetzer N, Koekemoer LL: DDT and pyrethroid resistance in Anopheles arabiensis from South Africa. Parasites \& Vectors 2013, 6(1):229.

76. Witzig C, Parry M, Morgan JC, Irving H, Steven A, Cuamba N, Kerah-Hinzoumbé C, Ranson H, Wondji CS: Genetic mapping identifies a major locus spanning P450 
clusters associated with pyrethroid resistance in kdr-free Anopheles arabiensis from Chad. Heredity 2013, 110(4):389-397.

77. Vannini L, Reed TW, Willis JH: Temporal and spatial expression of cuticular proteins of Anopheles gambiae implicated in insecticide resistance or differentiation of $\mathbf{M} / \mathbf{S}$ incipient species. Parasit Vectors 2014, 7:24.

78. Cinege G, Zsámboki J, Vidal-Quadras M, Uv A, Csordás G, Honti V, Gábor E, Hegedüs Z, Varga GIB, Kovács AL et al: Genes encoding cuticular proteins are components of the Nimrod gene cluster in Drosophila. Insect Biochem Mol Biol 2017, 87:45-54.

79. Vontas J, David JP, Nikou D, Hemingway J, Christophides GK, Louis C, Ranson H: Transcriptional analysis of insecticide resistance in Anopheles stephensi using cross-species microarray hybridization. Insect molecular biology 2007, 16(3):315324.

80. Koganemaru R, Miller DM, Adelman ZN: Robust cuticular penetration resistance in the common bed bug (Cimex lectularius L.) correlates with increased steadystate transcript levels of CPR-type cuticle protein genes. Pesticide Biochemistry and Physiology 2013, 106(3):190-197.

81. Nkya TE, Akhouayri I, Poupardin R, Batengana B, Mosha F, Magesa S, Kisinza W, David J-P: Insecticide resistance mechanisms associated with different environments in the malaria vector Anopheles gambiae: a case study in Tanzania. Malaria Journal 2014, 13(1):28.

82. Huang Y, Guo Q, Sun X, Zhang C, Xu N, Xu Y, Zhou D, Sun Y, Ma L, Zhu C et al: Culex pipiens pallens cuticular protein CPLCG5 participates in pyrethroid resistance by forming a rigid matrix. Parasites \& Vectors 2018, 11(1):6.

83. Wogulis M, Morgan T, Ishida Y, Leal WS, Wilson DK: The crystal structure of an odorant binding protein from Anopheles gambiae: evidence for a common ligand release mechanism. Biochemical and biophysical research communications 2006, 339(1):157-164.

84. Davies L, Williams DR, Aguiar-Santana IA, Pedersen J, Turner PC, Rees HH: Expression and down-regulation of cytochrome P450 genes of the CYP4 family by ecdysteroid agonists in Spodoptera littoralis and Drosophila melanogaster. Insect biochemistry and molecular biology 2006, 36(10):801-807.

85. Zhang H, Zhao M, Liu Y, Zhou Z, Guo J: Identification of cytochrome P450 monooxygenase genes and their expression in response to high temperature in the alligatorweed flea beetle Agasicles hygrophila (Coleoptera: Chrysomelidae). Scientific Reports 2018, 8(1):17847.

86. Arcà B, Lombardo F, Struchiner CJ, Ribeiro JMC: Anopheline salivary protein genes and gene families: an evolutionary overview after the whole genome sequence of sixteen Anopheles species. BMC Genomics 2017, 18(1):153.

87. Calvo E, Mans BJ, Andersen JF, Ribeiro JM: Function and evolution of a mosquito salivary protein family. The Journal of biological chemistry 2006, 281(4):19351942.

88. Bonizzoni M, Ochomo E, Dunn WA, Britton M, Afrane Y, Zhou G, Hartsel J, Lee $\mathrm{MC}, \mathrm{Xu}$ J, Githeko A et al: RNA-seq analyses of changes in the Anopheles gambiae transcriptome associated with resistance to pyrethroids in Kenya: identification of candidate-resistance genes and candidate-resistance SNPs. Parasites \& vectors 2015, 8:474.

89. Mitchell SN, Stevenson BJ, Müller P, Wilding CS, Egyir-Yawson A, Field SG, Hemingway J, Paine MJI, Ranson H, Donnelly MJ: Identification and validation of a gene causing cross-resistance between insecticide classes in Anopheles gambiae from Ghana. Proceedings of the National Academy of Sciences of the United States of America 2012, 109(16):6147-6152.

90. Edi CV, Djogbénou L, Jenkins AM, Regna K, Muskavitch MA, Poupardin R, Jones CM, Essandoh J, Kétoh GK, Paine MJ et al: CYP6 P450 enzymes and ACE-1 duplication produce extreme and multiple insecticide resistance in the malaria 
mosquito Anopheles gambiae. PLoS Genet 2014, 10(3):e1004236.

91. Stevenson BJ, Bibby J, Pignatelli P, Muangnoicharoen S, O'Neill PM, Lian LY, Müller P, Nikou D, Steven A, Hemingway J et al: Cytochrome P450 6M2 from the malaria vector Anopheles gambiae metabolizes pyrethroids: Sequential metabolism of deltamethrin revealed. Insect biochemistry and molecular biology 2011, 41(7):492-502.

92. Yunta C, Hemmings K, Stevenson B, Koekemoer LL, Matambo T, Pignatelli P, Voice M, Nász S, Paine MJI: Cross-resistance profiles of malaria mosquito P450s associated with pyrethroid resistance against WHO insecticides. Pesticide biochemistry and physiology 2019, 161:61-67.

93. Mastrantonio V, Ferrari M, Epis S, Negri A, Scuccimarra G, Montagna M, Favia G, Porretta D, Urbanelli S, Bandi C: Gene expression modulation of ABC transporter genes in response to permethrin in adults of the mosquito malaria vector Anopheles stephensi. Acta Trop 2017, 171:37-43.

94. Mastrantonio V, Ferrari M, Negri A, Sturmo T, Favia G, Porretta D, Epis S, Urbanelli S: Insecticide Exposure Triggers a Modulated Expression of ABC Transporter Genes in Larvae of Anopheles gambiae s.s. Insects 2019, 10(3):66.

95. Giraldo-Calderón GI, Zanis MJ, Hill CA: Retention of duplicated long-wavelength opsins in mosquito lineages by positive selection and differential expression. BMC Evolutionary Biology 2017, 17(1):84.

96. Leung NY, Montell C: Unconventional Roles of Opsins. Annu Rev Cell Dev Biol 2017, 33:241-264.

97. Hu X, Sun Y, Wang W, Yang M, Sun L, Tan W, Sun J, Qian J, Ma L, Zhang D et al: Cloning and characterization of NYD-OP7, a novel deltamethrin resistance associated gene from Culex pipiens pallens. Pesticide Biochemistry and Physiology 2007, 88(1):82-91.

98. Merrill CE, Pitts RJ, Zwiebel LJ: Molecular characterization of arrestin family members in the malaria vector mosquito, Anopheles gambiae. Insect molecular biology 2003, 12(6):641-650.

99. Merrill CE, Riesgo-Escovar J, Pitts RJ, Kafatos FC, Carlson JR, Zwiebel LJ: Visual arrestins in olfactory pathways of \&lt;em\&gt;Drosophila\&lt;/em\&gt; and the malaria vector mosquito \&lt;em\&gt;Anopheles\&lt;/em\&gt;

\&lt;em\&gt;gambiae\&lt;/em\&gt. Proceedings of the National Academy of Sciences 2002, 99(3): 1633 .

100. Li T, Liu N: Role of the G-Protein-Coupled Receptor Signaling Pathway in Insecticide Resistance. Int J Mol Sci 2019, 20(17):4300.

101. Li T, Cao C, Yang T, Zhang L, He L, Xi Z, Bian G, Liu N: A G-protein-coupled receptor regulation pathway in cytochrome $\mathbf{P 4 5 0}$-mediated permethrinresistance in mosquitoes, Culex quinquefasciatus. Scientific Reports 2015, 5(1): 17772.

102. Li T, Liu L, Zhang L, Liu N: Role of G-protein-coupled receptor-related genes in insecticide resistance of the mosquito, Culex quinquefasciatus. Sci Rep 2014, 4:6474.

103. Kodrík D, Bártů I, Socha R: Adipokinetic hormone (Pyrap-AKH) enhances the effect of a pyrethroid insecticide against the firebug Pyrrhocoris apterus. Pest management science 2010, 66(4):425-431.

104. Grönke S, Müller G, Hirsch J, Fellert S, Andreou A, Haase T, Jäckle H, Kühnlein RP: Dual lipolytic control of body fat storage and mobilization in Drosophila. PLoS biology 2007, 5(6):e137.

105. Caers J, Verlinden H, Zels S, Vandersmissen HP, Vuerinckx K, Schoofs L: More than two decades of research on insect neuropeptide GPCRs: An overview. Frontiers in endocrinology 2012, 3:151.

106. Plavšin I, Stašková T, Šerý M, Smýkal V, Hackenberger BK, Kodrík D: Hormonal enhancement of insecticide efficacy in Tribolium castaneum: oxidative stress and metabolic aspects. Comparative biochemistry and physiology Toxicology \& 
pharmacology : CBP 2015, 170:19-27.

107. Shafer OT, Kim DJ, Dunbar-Yaffe R, Nikolaev VO, Lohse MJ, Taghert PH:

Widespread receptivity to neuropeptide PDF throughout the neuronal circadian clock network of Drosophila revealed by real-time cyclic AMP imaging. Neuron 2008, 58(2):223-237.

108. Mertens I, Vandingenen A, Johnson E, Shafer O, Li W, Trigg J, Loof A, Schoofs L, Taghert P: PDF Receptor Signaling in Drosophila Contributes to Both Circadian and Geotactic Behaviors. Neuron 2005, 48:213-219.

109. Kunst M, Hughes ME, Raccuglia D, Felix M, Li M, Barnett G, Duah J, Nitabach $\mathrm{MN}$ : Calcitonin gene-related peptide neurons mediate sleep-specific circadian output in Drosophila. Current biology : CB 2014, 24(22):2652-2664.

110. Li Z, Zhang Y, An X, Wang Q, Khashaveh A, Gu S, Liu S, Zhang Y: Identification of Leg Chemosensory Genes and Sensilla in the Apolygus lucorum. Front Physiol 2020, 11:276.

111. Halon E, Eakteiman G, Moshitzky P, Elbaz M, Alon M, Pavlidi N, Vontas J, Morin $S$ : Only a minority of broad-range detoxification genes respond to a variety of phytotoxins in generalist Bemisia tabaci species. Sci Rep 2015, 5:17975.

112. Zhang Y-F, van Loon JJA, Wang C-Z: Tarsal taste neuron activity and proboscis extension reflex in response to sugars and amino acids in <em>Helicoverpa armigera $</ \mathbf{e m}>$ (Hübner). The Journal of Experimental Biology 2010, 213(16):2889-2895.

113. Gao Y, Kim JH, Jeong IH, Clark JM, Lee SH: Transcriptomic identification and characterization of genes commonly responding to sublethal concentrations of six different insecticides in the common fruit fly, Drosophila melanogaster. Pesticide biochemistry and physiology 2021, 175:104852.

114. Calvo E, Mans BJ, Ribeiro JMC, Andersen JF: Multifunctionality and mechanism of ligand binding in a mosquito antiinflammatory protein. Proceedings of the National Academy of Sciences 2009, 106(10):3728-3733.

115. Isaacs AT, Mawejje HD, Tomlinson S, Rigden DJ, Donnelly MJ: Genome-wide transcriptional analyses in Anopheles mosquitoes reveal an unexpected association between salivary gland gene expression and insecticide resistance. BMC genomics 2018, 19(1):225.

116. Elanga-Ndille E, Nouage L, Binyang A, Assatse T, Tene-Fossog B, Tchouakui M, Nguete Nguiffo D, Irving H, Ndo C, Awono-Ambene $\mathrm{P}$ et al: Overexpression of Two Members of D7 Salivary Genes Family is Associated with Pyrethroid Resistance in the Malaria Vector Anopheles Funestus s.s. but Not in Anopheles Gambiae in Cameroon. Genes (Basel) 2019, 10(3):211. 


\section{Figures legends}

Figure 1. (A) Functional classification of the 359 leg-enriched genes. Normalized expression levels (z-scores) for (B) detoxification enzymes and (C) cuticular proteins and (D) chemosensation-related proteins, Gene functions were obtained from the official An. gambiae gene annotation. Genes prefices are as follows: CYP - cytochrome P450s; UGT - UDP glucurunosyltransferases; COEAE - carboxylesterase; CPLC/CPR - cuticular proteins; CSP chemosensory proteins; OBP - odorant binding proteins; SAP - sensory appendage protein; Gr - gustatory receptors; IR - ionotropic receptors.

Figure 2. Number of differentially expressed genes $\left(\log _{2}|\mathrm{FC}|>2, \mathrm{FDR}<0.01\right)$ between VK7-HR (resistant) and the two susceptible strains, VK7-LR and N'Gousso. Upward arrows indicate over-expressed genes, whereas downward arrows represent under-expressed genes in $\mathrm{VK}_{7}-\mathrm{HR}$ compared to each of the susceptible strains.

Figure 3. (A) Functional classification of the 73 commonly up-regulated genes in the two comparisons related to constitutive resistance, VK7-HR vs VK7-LR and VK7-HR vs N'Gousso. Normalized expression levels (z-scores) for (B) detoxification enzymes and (C) cuticular proteins, Gene functions were obtained from the official An. gambiae gene annotation. Genes prefices are as follows: CYP - cytochrome P450s; UGT - UDP glucurunosyl-transferases; COEAE - carboxylesterase; CPLC/CPR - cuticular proteins. 
Figure 4. (A) Functional classification of the 159 commonly down-regulated genes in the two comparisons related to constitutive resistance, VK7-HR vs VK7-LR and VK7-HR vs N'Gousso. Normalized expression levels (z-scores) for B) odorant binding proteins and C) hormone activity-related genes. Gene functions were obtained from the official An. gambiae gene annotation. Genes prefices are as follows: DH31 - diuretic hormone 31; ILP - Insulin-like peptide; PKP - pyrokinin; Akh2 - adipokinetic hormone 2.ant binding proteins.

Figure 5. (A) Functional classification of the 348 up-regulated genes after 1hour of exposure to deltamethrin. Normalized expression levels (z-scores) of (B) detoxification enzymes, (C) G protein-coupled receptors, and (D) odorant binding proteins. Gene prefices are as follows: GPCR - G protein-coupled receptor; ABC - ATP binding cassette; CYP - cytochrome P450s; D7 - D7 salivary gland proteins; OBP - odorant binding protein.

Figure 6. Graphical depiction of the two main comparisons made and the main findings of each one. A. Constitutive resistance in multi-resistant VK7HR legs versus two susceptible counterparts (NG and VK7-LR) revealed enhanced phase I detoxification and cuticular genes, decreased hormonemediated metabolic processes and decreased expression of genes encoding odorant-binding and salivary gland proteins. B. Short-term deltamethrin induction in VK7-HR resulted in up-regulation of detoxification, with overrepresentation of transporters (Phase $\mathrm{o}$ and III), enhanced GPCR 
signaling, odorant-binding proteins and salivary gland proteins.

\section{Declarations}

\section{Acknowledgements/Funding}

This publication was supported by the project Research Infrastructures for the control of vector-borne diseases (Infravec2), which has received funding from the European Union's Horizon 2020 research and innovation program under grant agreement No 731060. (constitutive resistance and short-term induction transcriptomic data). Whole body vs leg was funded by an MRC Skills Development fellowship [MR/Ro24839/1] to VAI.

This study is co-financed by Greece and the European Union (European Social Fund) through the operational programme 'Human Resources Development, Education and Lifelong Learning' in the context of the project 'Strengthening Human Resources Research Potential via Doctorate Research' (MIS-5000432), implemented by the State Scholarships Foundation (IKY) (M.K.). This project has received funding from the Hellenic Foundation for Research and Innovation (HFRI) and the General Secretariat for Research and Innovation (GSRI), under grant agreement no. 2040 (V.B.).

\section{Authors' Contributions}

JV and MK conceived of the study. MK and VI performed the experiment, JC, VI and PI analysed the data. MK and JC prepared the required figures. MK, JC, VI, PI, VB, HR and JV drafted the manuscript. All authors read and approved the final manuscript. 


\section{Ethics declarations}

Ethics approval and consent to participate

Not Applicable.

Consent for publication

Not Applicable.

Competing interests

The authors declare that they have no competing interests.

\section{Availability of data and materials}

The Banfora whole-body RNA-seq data have been submitted to NCBI SRA under the BioProject accession number PRJNA75025, while all the other RNA sequencing data have been submitted under the BioProject accession number PRJNA764470. 


\section{Supplementary Files}

This is a list of supplementary files associated with this preprint. Click to download.

- Additionalfile1.pdf

- Additionalfile2.xls 